\title{
Musical and Intellectual Values: Interpreting the History of Tonal Theory
}

\author{
By Scott Burnham
}

For many years, the history of music theory seemed most useful as a source for dissertation topics, the models of choice being the critically annotated translation of some little-read treatise, "book report"-style coverage of a wider range of a theorist's work, or sometimes the tracing of a concept or category through several generations of theorists (sonata form, or the ${ }_{4}^{6}$ chord). The unstated assumption that there would be little overwhelming relevance in such topics guaranteed their suitability as journeyman demonstrations of scholarly aptitude. Students could safely work in distant tributaries, away from the roaring cataracts of central issues. Intellectual investment would be limited to showing a consciousness of the relationship of such tributaries to the main stream, either by locating originary traces of modern theories or by indulging in the compensatory satisfaction of being able to appraise earlier theories as primitive and unenlightened. But as more and more theorists have been brought to light in this manner and the list of critical editions grows, there is an equally growing apprehension that the history of our theoretical assumptions has moved closer to the center of our concerns in musicology. For as we become increasingly self-aware of the ways we talk about music, as talk about music eclipses music itself as the most fascinating object in the academic firmament, the history of such talk suddenly assumes a luminous relevance.

If music claims any place at all in academic discourse, it is as a cipher whose history is one of ever changing investiture. The study of the history of music theory enjoys the closest view of the parade route of authorities that have been vested in music and allows for an examination of the intellectual and ethical motivations behind them. Nature, Reason, Physiology, Psychology, Theology, and Human Cognition stand among these authorities, each variously appealed to in various ages. Music is alternately a force of nature, a product of reason, or an expression of the transcendent; it is a human practice, a product of cognition, and an expression of the creative psyche. What remains throughout any combination of these attributions is the invariably unshakable yet variably supportable belief that music is of fundamental importance to the human condition, and the history of its theory is largely the history of underwriting this belief in music's value through analogies with other currently meaningful human activities. We clearly feel the substantiality of music and yet, like Chamisso's 
Peter Schlemihl, it casts no shadow. As a hedge against the abiding fear that music has no communicable meaning that can be the subject of reasoned discourse (and consequently the fear that it may in fact have no "real" importance), music theory strives to give music back its shadow. ${ }^{1}$

Highly valued but equivocally grounded, music becomes a magical presence inviting both awe and anxiety. ${ }^{2}$ As a natural response to this view of music, music theorists have sought time and again (with all the earnest demeanor of blind, or perhaps bad, faith) to attach musical practice to esteemed cultural ideals: the agenda behind the construction of a music theory is very often one of fitting an existing practice to some sort of idealized intellectual model. This is increasingly found to be the case in medieval and renaissance theories, which up until recently have been examined primarily for clues about performance practices. Accounts of practice in the treatises of those periods reveal puzzling anomalies when attempts are made to reconstruct the moribund traditions they presumably expound. ${ }^{3}$ For music theory is never purely an act of codification, as it is sometimes portrayed (Fux as the codification of Palestrina, or, closer to home, A. B. Marx as the codification of Beethoven); mixed with the urge to account for what is vital in any given composer or style is the urge to idealize musical practice in ways congruent with one's world view.

In fact, the perception of just what is vital in a musical practice is often dictated by what is vital to one's value system (that which appears to be alive in one's necessarily selective field of vision). To take but one example, J. P. Rameau's entire theoretical oeuvre hums with the tension between empirical practice and the assumption of Cartesian ideals; vital to Rameau in the burgeoning tonal practice of his age is the susceptibility of harmonic syntax to generalization. He noticed that a pervasive aspect of musical practice, the dominant-tonic cadence, could act as a model for all other harmonic progressions and as a musical/empirical representation of the nature of pitch itself (the fifth returning to its source), thus allowing the semblance of a deductive system. ${ }^{4}$ An element of practice and an intellectual model attract each other, and an inevitable host of adjustments are made to preserve the marriage.

This continued tension between musical practice and intellectual model claims central importance in the history of music theory. Equal consideration to both factors is rarely granted in studies of the history of theory: either an earlier theorist's effectiveness in accounting for a particular musical practice is gauged by the nearest available lights, namely the perceived effectiveness of one's own theory, or the nature of his theory is explained primarily as a result of intellectual influences. These latter explanations are often based on similarities in language between a theorist and some philosopher, for example. Once such similarities are detected, 
the works of the theorist in question are then ransacked for other such evidence, and an interpretation based on influence arises. This kind of interpretation is then employed either to explain what is inadequate about a theorist (as in interpretations of A. B. Marx as a contradictory mix of Hegel and Goethe) or to show how a favored theorist is grounded in a venerable philosophical tradition (as in depictions of Schenker as Goethean or Kantian). ${ }^{5}$ Academically feasible evidence is found for pre-existing value judgments.

One way to avoid a premature or prejudicial assessment of influence as well as to keep in one's sights the mutually interactive confluence of praxis codification and intellectual model is to investigate first and foremost what a theorist in fact does rather than what he says he is doing or what one wishes he had done. The surest way to determine what a theorist does is to determine how he engages musical practice-what kinds of things are ascribed to that practice? how is the practice conceptualized? ${ }^{6}$ Only after a theorist's intellectual engagement with practice is understood in some internally logical way can that theorist's work stand open for an investigation of influence. As Allan Keiler puts it, in a discussion of philosophical influence on the different stages of Schenker's theory: "the whole question of influence can be confronted squarely only when each stage is understood synchronically in some coherent (or not coherent) way and when a comprehensible internal logic of development of such stages points the way to just those problematic areas whose understanding can come only from the outside." In short, to echo Roman Jakobson (and Saussure before him), you have to know what the points are before you can draw lines between them.

An understanding of synchronic "internal logic" in a theorist's work is facilitated when the music under examination is still part of a viable tradition. The history of tonal theory is thus of particular interest to us today, for its object of study is a music not only with which we are abundantly familiar, but which continues to bear the main argument of musical tradition in the modern West. Our study of the history of this music's theory is not directed toward reconstructing an unavailable musical experience, as has been the case with some branches of early-music history of theory (the efficacy of which is questioned above). We can instead approach earlier tonal theorists with our own internalized assumptions about the music they are attempting to understand-we are thus in a better position to gauge the shape of their endeavors, for we have the shape of our own as a ready comparison.

Of course this reliance on a shared tradition as rapprochement will easily lead to unproductive assessments of earlier theorists if the shape of our own concerns is treated as the desired standard against which earlier work 
is measured. There is no surer way to guarantee a complete misunderstanding of a theorist working from another standpoint than to measure it against one's own in this way. The model for this procedure is of course the now outmoded essentialist view of the history of science: the shared tradition of music is treated like a product of the natural world, the understanding of which is increasingly refined by subsequent generations of scientist-theorists. Thus we read about what Rameau got right (inversion theory) and what he got wrong (suspensions); or what Riemann got right (harmonic function), and what he didn't (dualism).

We need to be more concerned with understanding the history of music theory as an intellectual and cultural history than with constructing the pre-history of today's theory. This shift in emphasis would involve treating all theories as systems of thought with their own integrity and as cultural/ historical products with their own ways and means. Our present theoretical prejudices can start a dialogue with the earlier theory, in the manner of a hermeneutic exchange. Such an exchange would take the shape of a questioning, starting (most profitably, according to Thomas Kuhn) with those aspects of the earlier theory which seem to stand in greatest contradiction to our own views. ${ }^{8}$ The hermeneutic exercise then involves arriving at an understanding of the other theory that makes any apparently refractory aspects necessary, or at least relevant, to that theory. We thus move away from "why does Riemann insist on dualism?" as a rhetorical question along the lines of "why does he continue to bet on a lame horse (when he has a stable of winners)?" to "why does Riemann need dualism?" as a real question with the possibility of a revealing answer. Our question would then take the form of "why does his horse seem lame to us and a winner to him?" leading to "on what kind of race track would such a horse prove a winner?"9 Every test of an earlier theorist's assumptions is thus at the same time a test of our own assumptions. The result would be a more integrated view of ourselves as historical beings: instead of living within a disconnected present in need of a constitutive past we would be part of a present vitally connected to the past. Our own assumptions thus relinquish the role of a prescriptive template and become as historically conditioned as those of earlier theorists. This is in fact what we share, nolens volens, with those who have preceded us: we too attempt to understand music from a specific vantage point along the same historical continuum.

$* * *$

A few examples may illuminate the opportunites afforded by an interpretive study of the history of theory. The first takes the form of a vignette on the subject of Rameau and the suspension, in which an attempt will be 
made to counteract the standard type of assumption about earlier theorists made from the essentialist standpoint. Rameau's explanation of the suspension, taken from his first and most influential theoretical work, the Traité de l'Harmonie (1722), offers a clear case of an explanatory strategy that would never occur to us today. In the Traité, what we would deem a melodic suspension is for Rameau the result of the supposition (sub-position) in the continuo bass of a supernumerary tone beneath the fundamental bass. The rule behind such a reading states that in accordance with the so-called senario there can be no chord which exceeds the octave; therefore, the existing bass note cannot be the true fundamental. And the assumption behind this rule is that any simultaneous combination of tones found in a piece of music is perforce harmonic in nature, because nature, in music, is harmonic. The demonstrable relation of a major triad to the physical properties of regularly vibrating sound makes harmony a workable bottom line for a Cartesian deductive process.

Example 1. From Jean-Philippe Rameau, Treatise on Harmony, trans. Philip Gossett (New York: Dover, 1971), 90.

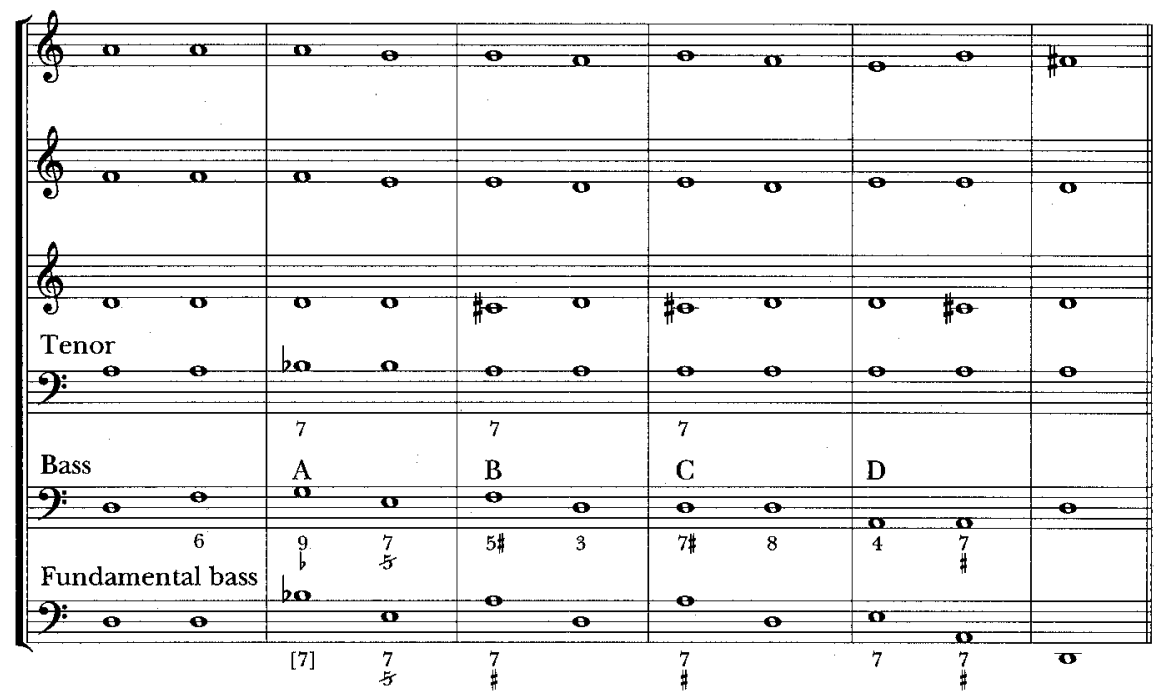

In Example 1, Rameau's notion of a supposed bass is useful in that it allows him to generalize about the other parts. The three upper parts of the chords at A, B, and C, when construed as forming a stack of three thirds with the fundamental bass, behave like the voices of a dominant seventh chord. Here Rameau, as a would-be deductive theorist, meets the challenge of showing how the apparently melodic practice of suspension can be harmonically generated-his explanation preserves normative fun- 
damental bass harmonic syntax (root motion by fifth). Yet even if we accept Rameau's explanation for chords A, B, and C, we may have more trouble with the chord at $\mathrm{D}$, where we find what we would clearly deem a cadential suspension. Rameau places it in the same class as the other chords by supposition, stating that for reasons of undue harshness this particular chord omits some of its natural chord tones ( $G$ and $B$, the remaining tones of a seventh chord built on $\mathrm{E}$ ). Since it is not divided in thirds like the other chords, Rameau labels the chord at D a heteroclite, an anomaly. ${ }^{10}$ The theoretical 'jehavior of this chord, as an $\mathrm{e}^{7}$ progressing to $\mathrm{A}^{7}$, is more abstract than in cases $\mathrm{A}, \mathrm{B}$, and $\mathrm{C}$-there is less evidence on the musical surface of the underlying seventh chord. Here we see the strength of Rameau's allegiance to his intellectual model: he willingly considers as a morphological anomaly that which in practice is an extremely common occurrence (the 4-3 cadential suspension). If we view his explanation from the standpoint of this allegiance, we can understand why he would so construe a musical phenomenon that seems to us so transparently otherwise. ${ }^{11}$

In subsequent treatises Rameau appears to come closer to a melodic concept of suspension. In his Génération Harmonique (1737), after declaring that the suspension is a dependent consequence of supposition, ${ }^{12}$ Rameau nonetheless describes the suspension as follows: "The suspension consists in holding over [literally: conserving] as many harmonic tones of a chord as one wishes, in order to make them heard in the place of those which would sound in the following chord, the root of which is generally employed at the same time in the Basso Continuo, on condition that the held tones can move diatonically to those that they suspend while the root of these latter tones continues to sound." 13 And in the following example (which accompanies these passages in the treatise) Rameau remarks that the case at letter $J$ must be regarded as a suspension rather than as a supposition. ${ }^{14}$

Example 2. From Rameau, Génération Harmonique, ex. XXIII.

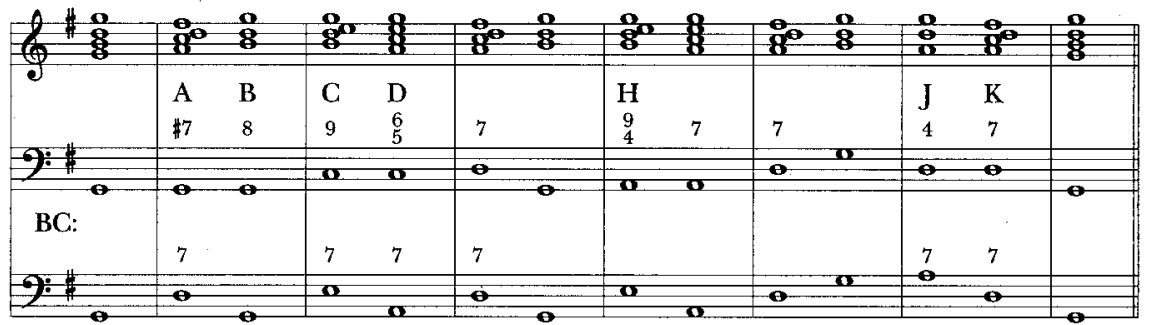

BF: 
Yet what is interesting in this example is not that Rameau finally seems to approach our own melodic view of a cadential suspension but that he felt the need at all to distinguish between supposition and suspension immediately after he had defined the latter as a dependent symptom of the former. In other words, whereas before all cases of suspension were explained as symptoms of supposition, it now appears that one can distinguish some cases as suppositions and others as suspensions. What lies behind this inconsistency?

I would argue that it is indicative of a tension between the analytical roles of the Basso Continuo (BC) and the Basse Fondamentale (BF). Rameau's recognition of the suspension is really an acknowledgment that some musical passages are best understood in terms of the BC. In the Traité example, and in cases $\mathrm{C}$ and $\mathrm{H}$ of the Génération Harmonique example, the BF allows an analysis of each passage showing it to be in conformance with generalized harmonic behavior. The supposed bass note in the BC is described as a supernumerary sound (yet related to the chord that follows as an anticipation). At letter $\mathrm{J}$, the $\mathrm{BC}$ (D), according to Rameau's above description of the suspension, acts as the root-yet there is an $\mathrm{A}$ in the $\mathrm{BF}$ (which results in a root progression rare for the $\mathrm{BF}$, that of a rising second). Rather than say that $\mathrm{BC}$ and $\mathrm{BF}$ are one here, Rameau says that the root is employed in the $\mathrm{BC}$-while the $\mathrm{BF}$ hangs on as a less significant placeholder, a theoretical root from a different conceptual dimension. Thus the $\mathbf{B C}$ is clearly taking on an analytical role, as Rameau now distinguishes between cases that are best explained by the $\mathrm{BF}$ and those best explained by the BC. Suspension is a BC phenomenon, supposition a $\mathrm{BF}$ phenomenon. For Rameau, letting the $\mathrm{BC}$ determine the nature of the progression at $\mathrm{J}$ allows that progression to be understood as a normative dominant-to-tonic cadence with a slightly prolonged and decorated dominant. ${ }^{15} \mathrm{By}$ leaving the $\mathrm{A}$ in the $\mathrm{BF}$, he seems to argue that while what is happening at $\mathrm{J}$ is primarily a suspension, it is still in some secondary sense a supposition, thus reversing his previous position.

These equivocations mark Rameau's struggle with two different levels of his analytical method: an analytical bass that shows the fundamental derivation of the sounds on the musical surface in relation to a deductive system of harmony contends with an analytical bass that generates the simplest practical descriptions of the linear behavior of those sounds. ${ }^{16}$ This is a central tension in Rameau, one that would be missed were we to comb his later work for clues to a closer propinquity to our own views about suspensions (and then rely on a crassly applied evolutionary model to support Rameau's "improving" views). The tension between BC and BF is the most visible manifestation of the underlying tension between musical practice and Cartesian deduction as available epistemological bases in 
Rameau's theoretical work. ${ }^{17}$ In terms of intellectual history, this reading of Rameau links his work to an age when systematic thought tacked a sometimes ambiguous course between the perceived tidal forces of deduction and induction, the age of both Descartes and Newton. ${ }^{18}$

$$
* * *
$$

After sketching just one symptomatic complexity of the issues Rameau was dealing with, it will be a bracing contrast to jump to a view of Rameau from the opposite end of the tonal theory spectrum, namely to Heinrich Schenker's version of Rameau's role in the history of theory. Here our emphasis is not on how a theorist engages music but how he engages the history of theory. An attempt to understand Schenker's fashioning of that history can reveal much about his own theory and its value system. At the same time, our discussion will mark the growing trend to address what is perhaps the most immediately pressing need in the history of tonal theory, namely, the formation of a historical perspective on Schenker. ${ }^{19}$ Such an approach would register as self-examination, for we still live in the Age of Schenker-his teachings have filtered into our daily talk about Western art music as pervasively and imperceptibly as those of Freud in our talk about human behavior.

In his essay "Rameau oder Beethoven? Erstarrung oder geistiges Leben in der Musik?" Schenker interprets the history of theory as that of a fall from grace. "Before Rameau," Schenker claims, "theory and composition were still a unity: both exclusively embraced voice leading." 20 Rameau's theory brought on a schism; his ill-conceived theory of harmony led to mechanical torpor. At the same time, however, music itself began to partake of spiritual life: "Suddenly an art form grew up, which, while appealing figuratively to the motions of the human soul by means of the material [sinnlich] living motion of the horizontal spans that are uniquely its own, certainly had to rank as the most autonomous and most sublime of all the arts. ${ }^{21}$ Echoing Riemann's primary objection to Rameau, Schenker cites Rameau's notion of chord structure by thirds as the scion of a misbegotten race of mechanical theories of vertical chord structures. The vertical in music is Erstarrung; the horizontal is geistiges Leben-note the association Schenker makes between horizontal Züge and the motions of the soul. French theory leads to death; German music is the life of the spirit. But Schenker's target is larger than French theory. In a strikingly Marxist interpretive move, Schenker relates Rameau's theory of inversion to the French Revolution ("Unten ist oben und oben ist unten!"), and dismisses both, along with the entire French Enlightenment, as evidence of "französisches Mittelmaß" over and against "deutsche Genie." France's vaunted rationality clearly plays the serpent in Schenker's Garden of Eden, 
turning man away from natural genius toward a specious Tree of Knowledge.

Schenker then positions himself as a Messianic figure who will heal the schism and once again unite theory with art, who will bring the word of Genius to Man after the Fall. ${ }^{22}$ This is why he needs to view the history of tonal theory as a schism. His simplistic dichotomies of theory and musical art, mechanical chord structure and living voice leading, French mediocrity and German genius-they all work to the end of articulating a crisis to which his theory provides a synthesizing answer. Not a little of Schenker's fervor could be dismissed as the consolatory ravings of a failed composer in an age of failed composition; he is thus easily attracted to a Romantic notion of recovering a lost and glorious past, and of showing his citizenship rights in the realm of genius. Now that theory has again become an art, theorists can take up residence alongside musical genius. Schenker's synthesis of the schism between theory and musical art is treated as a creative breakthrough very much like the artistic synthesis he so admires in the great composers.

But why the distasteful political framework; why is genius German, mediocrity French? Is this dichotomy simply a dire result of the post-World War I political atmosphere in Germany, or are there other factors that make this equation so automatic for Schenker?24 Any complete answer would entail nothing less than a cultural history of Germany from at least the eighteenth century to the twentieth. This is a history characterized by the interweaving of the ideas of genius, spirit, universality, and national identity. German intellectuals in the late eighteenth and early nineteenth centuries were in the process of building a cultural nation based on spiritual affinity, a kind of spiritual Heimat whose ancestor was the Hellenic Golden Age. By about 1800 music became a leading metaphor for spirit, the cultivation of music a metaphor for spirituality. As the primary locus of German profundity and universality, German music was the heart of a spiritual nation felt to be not only universal but distinctly ethnic at the same time. ${ }^{23}$ Exultantly possessed by this thought, Schenker quotes these words of Schiller: "Every nation has its day in history, but the day of the Germans is the harvest of the whole." ${ }^{25}$

But music wasn't always the mode of this universal spirit. In the Goethezeit it was much more clearly the German language itself that bore that spiritwitness the emancipation from French letters mounted in the age of Lessing, the subsequent translations of Shakespeare and the Persian poets, the agenda behind journals such as Goethe's Propyläen and the famous Athenaeum, and other attempts to associate German culture with the revered culture of ancient Greece (culminating latterly in Heidegger's linguistic speculations on the close relation between German and Greek as 
agglutinative tongues). Germany inherited from Greece the model for its self-imposed role as a universal culture, or at least as the epitome of Western culture.

Thus the attachment of these ideas to German nationalism is not just the result of post-World War I nationalist fervor, but is constitutive of German cultural history from at least the Deutsche Klassik, the age of Goethe and Schiller, Herder and Winckelmann. Perhaps the luridly emotional form this trend takes in Schenker's essay is engendered by the feelings of betrayal in Germany after the war (and by the latitude allowed such feelings, even in intellectual circles), but the basic assumption of a spiritual homeland that is associated with German culture is in place long before any militaristic manifestations of nationalism (which are often deemed its natural consequences) and serves far different purposes. Only the close association of cultural spirit with German national identity could ensure the ease with which enemies of the state become for Schenker enemies of the spirit. And France, with its history of rational prowess (its tongue long reputed to be the very language of rational thought), makes perhaps the readiest antithesis to the mysteries of German spiritual profundity, mysteries most closely preserved in its music.

These issues-the German question, canon formation, and spirituality in music-are central to the recent history of tonal theory and to our continued engagement with that history. The praxis that theorists such as Riemann and Schenker attempt to account for is fraught with valuations of spirit and culture that remain acutely alive and exposed in the late twentieth century. We as musical academics in the age of Schenker are fully implicated; we need to look at ourselves in just the ways that an interpretive study of the history of theory makes possible. We do so not to turn away in disgust from the tradition of the canonic masterpiece and its theories but to learn why we have loved this tradition, and what we can continue to love in it, in the manner of children who have just learned to see their parents as fallible humans, that is, as real historical beings rather than timeless entities. It is thus that we as a humanistic discipline may begin to grow up, take the measure of our abiding tradition, and assume our place, for better or worse, in the history of the Western world.

\section{NOTES}

1 This analogy is made more interesting by the fact that legendary figures who lose their shadows (or their reflections) do so as a pledge to the Devil in exchange for some sort of power (as in E. T. A. Hoffmann's Die Abenteuer der Silvesternacht or, more broadly, in vampire legends). Music thus figures, and is treated, as a powerful force that cannot be safely anchored in the normal world of objects, light, and shadows. Its propinquity to evil in writers as diverse as Plato and Thomas Mann is no coincidence.

2 In this light, the role of philosophy as an intermediary between man and the external 
world seems a nearer analogy to music theory than that of science, for music shares with philosophically conceived reality the same paradoxical combination of otherness and relatedness, exteriority and interiority. This is to distinguish a philosophical relation to the world from the largely dichotomous, subject/object relationship of science and the real world, defined by the ever present elements of technology and control. Philosophical assessments of the world are more likely to engage what it means to "be" in the world rather than what it means to "have" a world at one's disposal. Of course recent science has changed in this regard, but the science that is commonly associated with music theory is a more classical model.

3 The relation of theoretical prescriptions and intellectual models in early medieval theory is discussed by David E. Cohen in "Metaphysics, Ideology, Discipline: Consonance and Dissonance in the Theory and Practice of Western Polyphony," a paper read at the Princeton University Music Department Colloquium on 7 May 1993.

4 See Thomas Christensen's impressive "Science and Music Theory in the Enlightenment: D'Alembert's Critique of Rameau” (Ph. D. dissertation, Yale University, 1985) for a more in-depth view of Rameau's alleged Cartesianism.

5 Although a dauntingly relentless and impressively thorough study, Kevin Korsyn's "Schenker and Kantian Epistemology," Theoria 3 (1988): 1-58, seems motivated primarily by the need to overturn common objections to Schenker.

6 A brilliant example of this type of assessment is provided by Joseph Dubiel in "When You Are a Beethoven': Kinds of Rules in Schenker's Counterpoint, Journal of Music Theory 34 (1990): 291-340. Dubiel shows the central and abiding importance of the concept of the passing tone for Schenker's theory and does so with close readings of many examples from Schenker's counterpoint treatise in which he attempts to find out why Schenker sees things the way he does rather than instantly interpreting everything as either leading to or hindering the development of Schenker's "mature" theory.

7 Allan Keiler, "The Origins of Schenker's Thought: How Man is Musical," Journal of Music Theory 33 (1989): 274.

8 "When reading the works of an important thinker, look first for the apparent absurdities in the text and ask yourself how a sensible person could have written them. When you find an answer, ... when these passages make sense, then you may find that more central passages, ones you previously thought you understood, have changed their meaning." Thomas Kuhn, The Essential Tension (Chicago: University of Chicago Press, 1977), xii.

9 I sketch a possible answer to this specific question about Riemann in "Method and Motivation in Hugo Riemann's History of Harmonic Theory," Music Theory Spectrum 14 (1992): 9 n.

${ }^{10}$ This is originally a Greek word meaning "inclined differently." It was used in grammars to denote a word of irregular declension or inflection, and from there has assumed the general figurative meaning of exceptional or anomalous.

11 The reaction to Rameau's explanation of suspension that is precluded by a hermeneutic approach is exemplified in the following passage from David Beach's "The Origins of Harmonic Analysis," Joumal of Music Theory 18 (1974): 282: "Rameau's explanation of suspensions reflects his conception of harmony as being separable from counterpoint. The chord, as isolated from its context, is considered synonymous with 'harmony'; this is a fundamental error in his approch to musical syntax."

12 "La Supposition prend sa source dans l'un des Sons de la proportion Arithmétique ajouté au-dessous de la proportion Harmonique; la Suspension n'en est qu'une Suite." Génération Harmonique ou Traité de musique théorique et pratique (Paris, 1737), 158.

13 Ibid., 161-62. "La Suspension consiste à conserver autant de Sons Harmoniques que l'on veut d'un Accord, pour les faire entendre à la place de ceux qui doivent exister dans 
l'Accord suivant, dont pour lors le Son fondamental est généralement employé dans la Basse continue, pourvì que ces Sons conservés puissent arriver Diatoniquement à ceux qu'ils suspendent, pendant que le Son fondamental de ces derniers existe toujours."(Translation mine, as are all that follow).

14 "Le cas de J. doit être plutôt regardé comme Suspension, que comme Supposition." Ibid., 161.

${ }^{15}$ By preferring a simpler syntactic explanation of the sounds at $\mathrm{J}$ ( $\mathrm{V}$ to I rather than II to $\mathrm{V}$ to I), Rameau could be said to be wielding Ockham's razor, an intellectual reflex (andsignificantly-an inductive reflex) which may well have justified for him the discrepancy between $\mathrm{BC}$ and $\mathrm{BF}$.

${ }^{16}$ Just for the record, Rameau defines suspension in linear terms already in the Traitébut he does so in Book III, the practical section of the treatise. See Treatise on Harmony, 298: "Chords by supposition serve only to suspend sounds which should be heard naturally. . . This will be found wherever these chords occur, if you examine them with respect to the basso continuo and not to the fundamental bass, which always represents the perfect harmony." Here the linear view of the suspension is recognized as a strictly practical conception and associated explicitly with the $\mathrm{BC}$, whereas the theoretical conception involves the supposition and the BF. Also notable is the implication that here the suspension is the desired effect, and as such is served by the supposition; in the theoretical explanation the supposition is prior and the suspension dependent. For the practicing musician, the melodic view of suspension is the conceptualization that is most directly conducive to playing such things oneself.

17 The confusion between BC and BF in Rameau is the subject of Allan Keiler's pioneering interpretation of Rameau's fundamental bass. See Keiler, "Music as Metalanguage: Rameau's Fundamental Bass," in Music Theory: Special Topics, ed. Richmond Browne (New York: Academic Press, 1981), 83-100. Keiler discusses the theoretical constraints which arise as the result of fashioning the $\mathrm{BF}$ both as musical part and as metamusical paraphrase, and he characterizes Rameau as "the first theorist to be confronted, in the area of harmonic analysis, with the fact that the surface details of a piece often obscure the extent to which any piece conforms to the general musical language" (p. 100).

${ }^{18}$ For a study of Rameau reception highly sensitive to the complex pull of these currents in French intellectual history see Thomas Christensen, "Music Theory as Scientific Propaganda: The Case of D'Alembert's Élémens de Musique," Journal of the History of Ideas 50 (1989): 409-27.

${ }^{19}$ Exceptional recent work in this regard includes Allan Keiler, "The Origins of Schenker's Thought," and Leslie David Blasius, "Evading Psychology: The Epistemology of Schenker's Kontrapunkt," a paper read at the 1989 Annual Meeting of the Society of Music Theory in Austin, Texas. Stephen Hinton is also at work on a forthcoming book dealing with the Americanization of Schenker.

20 "Vor dem Auftreten Rameaus waren Schaffen und Lehre eine Einheit immerhin: beide bekannten sich ausschließlich zur Stimmführung." Heinrich Schenker, "Rameau oder Beethoven? Erstarrung oder geistiges Leben in der Musik?" Das Meisterwerk in der Musik, vol. 3 (Munich: Drei Masken Verlag, 1930), 14.

21 "Auf einmal wuchs eine Kunst heran, die . . mit der sinnlich-lebendigen Bewegung der ihr eigenen horizontalen Züge auch die Menschenseele in ihren Bewegungen gleichnishaft ansprechend, unter sämtlichen Künsten wohl als die unabhängigste und erhabenste gelten dürfte." Ibid., 15.

22 "Nur ein Christus konnte Tote erwecken-nur Geist allein könnte die Menschheit noch einmal zur Genie-Musik, dem einzig wahren Leben in Musik erwecken.” Ibid., 19.

${ }^{23}$ In an unpublished paper entitled "On the Task of the Music Historian: The Myth of the Symphony after Beethoven," Sanna Pederson develops the idea of Germany as a cultural 


\section{GurRent Musicology}

nation in the context of a striking critique of Carl Dahlhaus and the myth of the symphony.

${ }^{24}$ The effects of World War I on Schenker's view of Rameau are discussed by Harald Krebs in his article, "Schenker's Changing View of Rameau: A Comparison of Remarks in Harmony, Counterpoint, and 'Rameau or Beethoven?'," in Theoria 3 (1988): 69ff.

25 "Jedes Volk hat seinen Tag in der Geschichte, doch der Tag der Deutschen ist die Ernte der ganzen Zeit." Ibid:, 23. 